\title{
Relações entre componentes curriculares e modos autorais de ensinar na alfabetização
}

\author{
Fátima Terezinha Spala
}

Secretaria Municipal de Educação do Rio de Janeiro

Maria Letícia Cautela de Almeida Machado

Professora Adjunta da Faculdade de Educação da Universidade do Estado do Rio de Janeiro

\section{Paula da Silva Vidal Cid Lopes}

Professora Adjunta da Faculdade de Educação da Universidade do Estado do Rio de Janeiro

\begin{abstract}
Resumo
Este artigo tem por objetivo discutir as relações entre os componentes curriculares e as estratégias didático-pedagógicas, na formação em serviço dos professores, visando os processos de alfabetização. Busca-se referências em estudos histórico-culturais e utiliza-se como metodologia uma investigação de base teórico-conceitual. Os resultados indicam que tal relação, na formação do professor, não precisa ser direcionada à eleição de um método de trabalho, mas sim de um conjunto de pressupostos e princípios que possam sustentar práticas contextuais, autorais, investigativas e diversificadas. Conclui-se que as questões didáticas precisam ser incorporadas à formação dos alfabetizadores como estratégias pedagógicas para o diálogo entre as diferentes culturas que se entrecruzam nas escolas.
\end{abstract}

Palavras-chave: Formação de professores; Componentes curriculares; Alfabetização.

\section{Abstract}

Relationship between curricular components and authorial modes of teaching in literacy

This article aims to discuss the relationships between curricular components and didactic-pedagogical strategies, in the in-service training of teachers, aiming at literacy processes. We look for references within historical-cultural studies, applying a methodology for research which is theoretical and conceptual based. The results indicate that such relationship, in teacher education, does not need to be oriented towards the election of a working method, but rather to a set of assumptions and principles that can sustain contextualized, authorial, investigative and diversified practices. Conclusion is that the educational issues need to be incorporated into the training of teachers as strategies that will foster dialogue between different cultures that intersect in schools.

Keywords: Teacher training; Curricular components; Literacy. 


\section{Resumen}

\section{Relaciones entre componentes curriculares y modos autorales de enseñar en la alfabetización}

Este artículo tiene por objetivo discutir las relaciones entre los componentes curriculares y las estrategias didáctico-pedagógicas, en la formación en servicio de los profesores, buscando los procesos de alfabetización. Se busca referencias en estudios histórico-culturales y se utiliza como metodología una investigación teórico-conceptual. Los resultados indican que tal relación, en la formación del profesor, no necesita ser dirigida a la elección de un método de trabajo, sino de un conjunto de supuestos y principios que puedan sostener prácticas contextuales, autorales, investigativas y diversificadas. Se concluye que las cuestiones didácticas necesitan ser incorporadas a la formación como estrategias para el diálogo entre las diferentes culturas que se entrecruzan en las escuelas.

Palabras clave: Formación de profesores; Componentes curriculares; Alfabetización.

\section{Introdução}

Apesar dos esforços das redes públicas de ensino para ensinar os meninos e as meninas do país e do empenho para gerar professores bem formados, os números vêm indicando que continuam sendo concebidos indivíduos que passam pelas instituições de ensino sem constituírem os conhecimentos escolarizados de base, dentre eles o mais fundamental de todos: a elaboração da leitura e da escrita. São milhares os alunos que vêm provocando e mobilizando os profissionais de Educação que, mesmo sem se darem conta de que o fracasso escolar é resultado de um projeto social excludente, enfrentam diária e corajosamente as demandas que impedem que as crianças aprendam. Ora imputando a si mesmos a responsabilidade pelo fracasso no desenvolvimento desse processo, ora apontando os alunos e seus familiares como os responsáveis pela superação de suas dificuldades. Esta situação tem levado os críticos mais apressados a estabelecerem uma relação direta entre a formação dos professores e o desempenho dos discentes, esperando verem revelada, nos índices de promoção dos alunos, a expressão do empreendimento depositado na formação dos professores.

De qualquer forma, independentemente do ponto de vista assumido para explicar o fenômeno complexo que constitui o fracasso escolar, os professores representam a linha de frente de qualquer mudança pedagógica que se pretenda na escola. Diante desse contexto, este artigo tem por objetivo discutir as relações entre os componentes curriculares e as estratégias didático-pedagógicas, na formação em serviço dos professores para os anos iniciais do Ensino Fundamental, na área de alfabetização. Para tanto, assume-se como opção metodológica o desenvolvimento de uma pesquisa 
de base teórico-conceitual, a partir de referencial histórico-cultural. Tal pesquisa insere-se em um cenário de investigações mais abrangente desenvolvido pelo grupo de pesquisa Linguagem, Cognição Humana e Processos Educacionais ${ }^{1}$. Em seu ciclo de estudos sobre a formação inicial e em serviço de agentes de letramento na Educação Básica, esse grupo investe na produção de estudos que possam contribuir para práticas de ensino diversificadas, democráticas e inclusivas.

\section{A formação em serviço}

Subjacentes à concepção de formação em serviço para professores, estão presentes alguns conceitos que marcam a implementação de políticas públicas para a área e refletem sobre a história da formação do magistério público no Brasil. A formação em serviço, com mais frequência, tem sido nomeada utilizando diferentes termos, como reciclagem, treinamento e, principalmente, capacitação. Essas concepções têm sido questionadas, tanto do ponto de vista conceitual, como em suas implicações teóricopráticas. É importante, portanto, analisá-las e compreender seus significados semânticos, uma vez que os conceitos implícitos revelam e influenciam as decisões tomadas, justificando as ações propostas. Esses termos têm alguns significados: 1) reciclagem: sugere que se comece sempre tudo de novo; 2 ) treinamento: destitui os profissionais de sua condição de seres humanos; 3) capacitação: traz a ideia de dar algo para aqueles que, do contrário, seriam incapazes (CANDAU, 1997).

No momento atual, parece haver consenso quanto à necessidade de formação continuada para profissionais da área da Educação. A questão é como e para quê. Quando pensamos especificamente em formação em serviço, para alguns, essa representa, ainda, uma prática compensatória em virtude de a formação inicial dos professores ser considerada insuficiente. É importante destacar que essa concepção parece trazer uma redução na concepção de formação docente, de modo a colocá-la somente no âmbito da capacitação.

É preciso considerar que a redução na concepção de formação docente, com ações fragmentadas, de caráter puramente funcional, é comprometida com um pragmatismo e gera casuísmo e descontinuidade. Essa descontinuidade vem sendo respon-

1 Este grupo de pesquisa, sob a liderança do professor doutor Luiz Antonio Gomes Senna, compõe a Linha de Pesquisa "Educação Inclusiva e Processos Educacionais" do Programa de PósGraduação em Educação da UERJ. 
sável por justificar, e manter a tradição do eterno recomeço, como se não houvesse história, processos e aprendizagens. Trata-se de substituir o conhecimento recém-adquirido pelo novo, desconsiderando o tempo transcorrido de vida, de profissão e os saberes adquiridos. Neste sentido, não só os alunos, mas também os professores estão fadados a voltar ao marco inicial, sempre ao ponto zero.

Diferentemente, as propostas de formação em serviço estabelecidas a partir de uma perspectiva formativa, defendida pelo conjunto deste trabalho, incorporam uma distinta dimensão aos processos de aprendizagem e desenvolvimento humano, valorizando a formação humana global e a autonomia intelectual dos professores como condição necessária ao redimensionamento da sua prática e ao respeito a seu exercício profissional.

Esse confronto expõe as contradições e os paradoxos dos modelos de formação em serviço. Tal formação tende a manter uma perspectiva reducionista quando não está em consonância com um projeto educacional global, ou mesmo na ausência de uma política de formação dos professores. Essas reflexões vêm provocando uma revisão profunda dos paradigmas teóricos que embasam os programas de formação e têm levantado questionamentos sobre determinadas concepções e práticas. Não basta dominar os processos que envolvem a relação ensino-aprendizagem. Tornou-se necessário redimensionar esses conhecimentos e situá-los historicamente, para garantir, a partir deles, a construção de uma matriz epistemológica constituída pela história e pela cultura.

De acordo com Góes (2000, p. 26), "Vygotsky propõe um programa metodológico que consiste em estudar o comportamento em mudança e as condições sociais de produção dessa mudança. Não podemos isolar o momento da ação de sua história nem isolar o sujeito do plano das interações” . Nessa concepção, o fazer pedagógico é a síntese da experiência histórico-cultural e não um momento abstrato e indeterminado de eterna preparação de uma aprendizagem estática. Essa noção processual e a crítica ao caráter puramente corretivo e pragmático dos componentes curriculares da formação dos professores representaram o ponto de partida para identificar alguns (des)caminhos da formação em serviço do magistério.

Entender a formação dos professores nesta perspectiva, como um processo contínuo, responsável por conferir ao professor autoridade para lidar com essa temporalidade do desenvolvimento humano, com suas especificidades e exigências, vem nos 
permitindo reconhecer os custos do caráter aligeirado e descontínuo dos modelos de formação que desconsideram o desenvolvimento. Essa compreensão vem exigindo um projeto de formação em serviço que redefina a atividade do professor, possibilitando-o estabelecer uma relação diferente com o conhecimento, em substituição às concepções mais tradicionais e tecnicistas. Esta relação, portanto, prioriza o papel das interações entre os sujeitos na constituição do conhecimento.

Outra questão que merece ser colocada em debate é a dimensão que a relação teoria e prática assume através dos componentes curriculares e ações de formação em serviço. Para alguém se tornar um bom professor, não basta o domínio de conteúdos específicos, técnicas e métodos pedagógicos, ambos conquistas de uma boa formação acadêmica. Da mesma forma, também não é suficiente apenas o conhecimento adquirido na prática para garantir uma formação docente consistente. Redimensionar a relação entre teoria e prática nas ações de formação dos professores significa atribuir à teoria o lugar das possibilidades, sem com isso supor que ela seja capaz de prever as situações e encaminhar soluções para o cotidiano da sala de aula ou mesmo que seja tratada como produção de exclusividade acadêmica. Também é importante reconhecer que nenhuma prática está isenta de alguma elaboração teórica, e que os conhecimentos teóricos precisam ser ressignificados diante da realidade escolar. Esse movimento propicia entender e reconhecer na prática um espaço de criação e reflexão, no qual os conhecimentos são gerados e ampliados, e não apenas aplicados.

Apenas assumindo esses pressupostos, e a partir deles, é possível superar a história de numerosos programas de formação de professores que priorizam a teoria em detrimento da prática, contudo, sem admitir exatamente o contrário, ou seja, a adoção de esquemas que supervalorizam a prática e desconsideram a importância e o lugar da formação teórica. Trata-se de reconhecer que teoria e prática estão em permanente ancoragem, e que é necessário aproximar os conhecimentos estabelecidos cientificamente às experiências e saberes constituídos na prática.

\section{A relação entre conteúdo e forma na formação do professor alfabetizador}

Em sentido específico, os componentes curriculares para a formação de professores representam algum tipo de domínio privilegiado para o desenvolvimento de uma pedagogia coerente com o ensino capaz de qualificar o sujeito no/para o mundo contemporâneo. Refletir sobre estes componentes, em sentido amplo, implica com- 
preender e considerar os interesses dos alunos e preocupar-se não só com os conhecimentos que se seleciona e sugere, mas, também, com a metodologia que os apresenta e essa relação precisa ser colocada em questão nas propostas de formação em serviço.

O problema fundamental, de natureza essencialmente ideológica, é o fato de que quem escolhe e seleciona os conteúdos a serem ensinados precisa definir, também, a favor de que, e de quem, está a forma que se escolheu para ensinar e apresentar conteúdos. Reconhecidamente, toda escolha metodológica articula uma posição política e revela teorias de compreensão e leitura das várias realidades. Logo, traduz as escolhas, os valores e as histórias dos professores, ou seja, expressa e revela a sua formação.

Contudo, é possível caminhar para superar uma concepção dicotômica que insiste em separar conteúdo e forma. Nesta perspectiva, a forma diz respeito às estratégias didático-pedagógicas e técnicas, e o conteúdo está relacionado aos conhecimentos e temas selecionados para serem ensinados. Ou seja, se os conteúdos selecionados para alfabetizar são motivados pela real necessidade dos alunos, a forma de ensiná-los precisa acompanhar e garantir vivências compatíveis com seus contextos de usos e funções sociais. Essa experiência pode e deveria ser viabilizada aos professores nos seus diversos momentos de formação.

Os currículos de formação em serviço ainda reservam muito tempo às discussões teóricas sobre metodologias pautadas em paradigmas tradicionais, reduzindo as questões de alfabetização ao debate entre métodos. Diante das grandes mudanças nas áreas tecnológicas, nas práticas culturais e nos vários sistemas de linguagem, incluindo a informática, a sociedade passa a exigir um homem mais integral, porém a escola não sabe como contribuir para a constituição deste novo homem. Do ponto de vista do conhecimento e da formação humana, os componentes curriculares precisam considerar a aplicabilidade à realidade vivida pelos professores, bem como a compreensão de como esse conhecimento se constitui e se modifica nos indivíduos.

O aparato técnico-pedagógico que compõe o repertório de ações didáticas do professor constrói-se, inicialmente, a partir dos programas de formação inicial, tendo origem em grande parte, portanto, na licenciatura em Pedagogia, nos poucos cursos de formação de professores em nível médio ou mesmo nos cursos adicionais de formação complementar destinados ao estudante que já concluiu outra graduação.

Já em atuação nas escolas, a formação continuada em serviço muitas vezes busca relacionar as ementas acadêmicas dos cursos de formação inicial aos projetos 
político-pedagógicos das escolas e às diretrizes curriculares firmadas por cada rede de ensino, seja pública ou particular. Essa relação se torna, muitas vezes, a adequação às diretrizes comuns, aos conceitos de sujeito e de formação escolar que se manifestam para além dos referenciais teóricos desse projeto, mas se fazem revelar no detalhamento de cada ação gestora em educação - dos órgãos centrais de gerência pedagógica ao gerenciamento diário do planejamento das aulas.

Recorrendo à história da alfabetização escolar no Brasil, desvelada por autores como Senna (1995; 2011), Mortatti (2000), Mendonça e Mendonça (2007), Carvalho (2003), Smolka (1993), entre outros, é possível observar que, a partir da década de 1990, sendo superados os métodos rígidos, genéricos e sequenciais, famosos nas cartilhas e manuais de alfabetização, os cursos de formação de professores acabaram por secundarizar a sistematização didática dos conteúdos, vinculada às questões do ensino.

A formação para o ensino e mediação do processo de alfabetização se tornou, desta maneira, volátil e pouco efetiva pelas mínimas chances que oferece ao professor para responder às demandas dos diversos modos de aprender e ensinar que os alunos e suas diferentes aprendizagens exigem. No que diz respeito aos referenciais teóricos em alfabetização, embora coadunem perspectivas de origens das mais diversas, é recorrente escutar de professores em formação continuada em serviço que tais teorias não lhes oferecem subsídios palpáveis para a realização de práticas coerentes com o cenário educacional em que atuam e tampouco lhes possibilitam romper com os conceitos mecanicistas de elaboração do conhecimento linguístico, no que diz respeito à cultura escrita.

Conforme difundido por Machado e Lopes (2015) e Spala (2015), a relação entre o conteúdo e a forma no processo de alfabetização não precisa ser direcionada à eleição de um método de trabalho, mas sim de um conjunto de pressupostos e princípios que possam produzir práticas autorais e contextuais de professores qualificados à atividade intelectual de sua função.

Cabe um esclarecimento preeminente quanto à escolha do termo alfabetização, presente no artigo. A escolha desse vocábulo não se justifica apenas pelo valor lexical, mas, sobretudo, pela necessidade de demarcar componentes específicos envolvidos na sistematização do processo de alfabetização. Neste entendimento, o processo de alfabetização compreende tanto a dimensão do estudante, que irá elaborar concei- 
tos em leitura e escrita, quanto a dimensão do professor, que, como mediador entre a cultura do aluno e a cultura escrita, organizará modos de ensino que proporcionem a elaboração destes conceitos.

É preciso ter em mente que o conceito de alfabetização na contemporaneidade vem exigindo englobar a complexidade dos novos sujeitos sociais, incorporando as dimensões políticas, culturais e sociais envolvidas. O ensino sistemático da língua escrita acontece nos primeiros anos do ensino fundamental, contudo, essa circunstância é potencializada e antecipada para o aluno que está imerso em uma rede de interações com letras e textos. A partir dessa compreensão, o uso da língua escrita deixa de ser uma decisão individual, e passa a ser o resultado de uma determinação social. Por ser um produto cultural complexo depende do ensino intencional e organizado, que se insere no tempo letivo e no espaço escolar, muito embora se considere o fato de que esse aprendizado não termina ao final do ano letivo, sequer tem seu início marcado com a entrada da criança na escola.

Alfabetizar é muito mais do que ensinar a soletrar e relacionar letras e sons, é colocar uma língua em funcionamento em todas as suas dimensões: fonética, fonológica, morfológica, sintática, prosódica, semântica e discursiva. Isso nos permite afirmar que estar alfabetizado implica saber ler e compreender o que se leu, e saber escrever exige organizar as ideias de acordo com as convenções, de modo a adequar os escritos à situação de comunicação e aos critérios estabelecidos.

A alfabetização pressupõe experimentações que possam ser produzidas no interior das escolas, como práticas de constantes possibilidades de uso da língua escrita, com originalidade e competência. Sendo assim, planejar o processo de alfabetização implica, necessariamente, considerar os contextos de produção de leitura e de escrita, priorizando os textos reais, e reconhecer os estudantes como pessoas que ajuízam e constituem estes conhecimentos, mesmo antes de se apropriarem das convenções da língua escrita.

Posto isto, as estratégias didático-pedagógicas para a implementação dos conteúdos voltados para a alfabetização podem ser contempladas na formação dos professores, a partir da coordenação dos seguintes componentes curriculares: a) Formação de conceitos em escrita alfabética e modos de ensinar e aprender; b) Modos de produção de escrita, de leitura e de oralidade. Entende-se, ainda, que tais aspectos podem ser trabalhados para além dos gestos articulatórios e gráficos, assumindo a corporeidade 
como caminho de interação com o mundo e, portanto, também com os conhecimentos.

No trabalho com esses componentes, a autoria do professor é premissa: na eleição dos pontos de apoio para as atividades, como projetos, temáticas ou textos motivadores; no planejamento das propostas pedagógicas; na elaboração ou seleção do material didático, dos conteúdos e das formas de fazê-los circular; na organização da rotina, dos materiais e dos grupos de trabalho; nas mediações entre os modos de elaborar os conhecimentos dos alunos e os modos convencionais.

\section{Formação de conceitos em escrita alfabética e modos de ensinar e aprender}

Desde a sua criação, a escrita alfabética padrão sempre representou um signo de poder. Por muito tempo, serviu para esconder aquilo que lhe fora confiado: ela não uniu os homens, ao contrário, surgiu para separá-los, confrontando os que a dominavam com aqueles cujo acesso era negado. Neste contexto, os conhecimentos que estão envolvidos na apropriação da escrita alfabética tiveram influência direta nas divisões e situações de exclusão sociais no mundo fundado a partir da Modernidade. Este modelo, que por anos apartou aqueles que dominavam a língua dita culta daqueles que tinham uma fala informal, tida como inferior, usada pelos grupos menos prestigiados, legitimou e serviu aos processos de hegemonia cultural e de exclusão.

Assim, a língua escrita sempre esteve recoberta de valores políticos e vem representando um fator de exclusão social, não real, mas idealizada em uma norma padrão. Pois que se determinou que só produz conhecimento quem escreve consoante aos parâmetros da cultura científica (MACHADO; SENNA, 2012).

A questão é que esta língua padrão não é a língua de fato, mas, conforme Bagno (2009), um modelo idealizado de língua certa, descrito e prescrito pela tradição gramatical normativa. Na verdade, a língua padrão é um arremedo de língua, é um sistema que foi constituído para forjar um sujeito social desejado - o homem cartesiano e seu pensamento científico. Assim sendo, conforme aponta Machado (2013), o aluno não reconhece na escrita padrão sua língua materna, pois, apesar de a língua escrita portuguesa ter uma representação fonética, isso não quer dizer que ela represente a língua oral.

A partir desse entendimento, e reconhecendo que a alfabetização pressupõe elaboração de conceitos por parte dos estudantes, considera-se que os alunos precisam 
ser desafiados a pensar tanto sobre os princípios linguísticos da escrita alfabética e sua relação com a oralidade quanto sobre a sua representação social. Estes desafios não se dão em unidades específicas do planejamento escolar, mas numa dinâmica pedagógica constante que convida os estudantes a colocarem em jogo suas concepções de escrita, de leitura e de oralidade, a compartilhar e argumentar sobre seus modos pessoais de interação com estes objetos. Assim, para que os estudantes pensem sobre a escrita e formulem conceitos, cabe planejar atividades através das quais tenham a oportunidade de ler e escrever à sua maneira ou do seu melhor jeito, colocando em xeque os conhecimentos que possuem sobre a língua escrita. A ideia que subsidia essa prática é a de alfabetização como um processo em permanente constituição, e não como um conhecimento que se recebe do professor.

A intervenção do professor, nesse ponto de vista, pode ser a de mediação de quem convida os alunos a refletirem sobre o sistema de escrita, levando-os a descobrirem as pistas com boas falas, boas dicas e desafiadoras perguntas para que expliquem como chegaram àquela resposta, seja a resposta certa ou não. O saber linguístico produz-se em processo de conhecer o mundo e de aprender a falar sobre ele, primeiramente, e, depois, a escrever sobre ele. Construir conceitos sobre a escrita alfabética sobrevém, portanto, à produção tanto de oralidade quanto de leitura e escrita.

Deste modo, entre os conteúdos a serem arrolados na formação de professores, é imprescindível que se coloque em debate a natureza alfabética e ortográfica do sistema de escrita. No entanto, mais do que abordar tais conteúdos, é necessário que a formação crie possibilidades para que o professor possa discutir e construir estratégias didático-pedagógicas que favoreçam aos alunos a construção de tais conceitos a partir de experiências com o texto, em práticas de leitura e escrita. Pois, conforme apontam os próprios PCN (BRASIL, 1997), o ponto de partida para o envolvimento do aluno com a escrita é o texto, e mesmo as práticas de reflexão sobre a língua devem ser contextualizadas e trabalhadas, de preferência a partir de textos orais/escritos.

Em concepções mais tradicionais, é difícil conceber a ideia de alfabetizar com textos antes mesmo de o aluno dominar a leitura e a escrita de palavras e frases convencionalmente. Entretanto, tomar o texto como ponto de partida e como objetivo, concomitantemente, é uma opção que vem acompanhada de estratégias que potencializam conhecimentos que os alunos já possuem, para, a partir destes, constituir novos conhecimentos. Não por acaso, grande parte dos materiais didáticos elaborados por professores, que tomam o texto como a unidade privilegiada de ensino, elegem textos 
de predominância na linguagem oral, para que os alunos o conheçam de cor e possam usar a memória para ajustar texto escrito e texto lido, para localizar palavras no texto, para comparar quantidade de letras das palavras, para ampliar o repertório de letras conhecidas, para desenvolver consciência fonológica, enfim, para pensar a língua escrita.

\section{Modos de produção de escrita, leitura e oralidade}

Produzir escrita no contexto escolar representa, em primeira instância, estar disponível para arriscar-se na cultura de outro alguém. Pressupõe permitir que esse alguém - quase sempre o professor - interfira num movimento pessoal de interação com uma nova possibilidade de diálogo com o mundo, que tanto difere da espontaneidade do dia-a-dia.

Na perspectiva teórica adotada neste trabalho, tudo o que é vivido incide diretamente na aproximação ou no distanciamento à cultura escrita. Assim, os sentidos atribuídos à escrita são os mais diversos, tornando-se inviável que todos os alunos de um mesmo ano de escolaridade construam escrita da mesma forma e ao mesmo tempo.

A diversidade de escritas que circula em sala de aula reflete a exata proporção da diversidade pedagógica que o professor precisará adotar e contemplar se quiser atender às diferentes formas de aprendizagens de seus alunos.

Numa turma hipotética de primeiro ano do ensino fundamental, pode ser necessário, por exemplo, promover propostas que desafiem alunos a desconstruírem suposições não alfabéticas de escrita, através de um trabalho que parte dos textos, promovendo análise de trechos, oportunizando a interação dos alunos com escritas alfabéticas. O objetivo deste tipo de prática é possibilitar que os alunos se arrisquem em modos inéditos, para eles, de interação com a escrita. A partir deste trabalho, pode-se avaliar a produção de escrita dos alunos, tomando como referência o texto anteriormente trabalhado, assim como a produção de escrita que tome como referência a estrutura do texto trabalhado acrescida da autoria dos alunos.

Nessa mesma turma, podem ser observados também alunos que já utilizam modos alfabéticos de produção de escrita e que demandam outro tipo de proposta pedagógica, pois seus textos revelam necessidade de adequação às convenções da escrita padrão, como questões ortográficas ou organização das ideias expressas na escrita. Posto isto, nota-se que as mediações dos professores contribuirão para a aprendiza- 
gem dos alunos se forem direcionadas às reais condições dos textos que produzem. Muitos outros comportamentos escritos podem compor essa lista hipotética e seria impossível citá-los aqui porque são tão diversos quanto os sujeitos que os produzem.

Contudo, como ainda há entre professores o desconhecimento sobre o que fazer com os textos, alguns passam a dar importância exagerada à interpretação superficial dos mesmos. Assim, os textos passam a servir de pretextos para se colocar em prática as atividades de alfabetização, que antes eram realizadas com o suporte das cartilhas. Dessa forma, a proposta de alfabetizar com textos é reduzida ao preenchimento de vazios, a partir de perguntas feitas com o propósito restrito de selecionar e buscar informações que estão explícitas no texto, sempre a partir da perspectiva do professor. Comumente, a obviedade das propostas não deixa espaço para a dialógica relação entre tex to e leitor, sobretudo nos textos literários que são os mais utilizados pelos livros de alfabetização. O gênero literário é o que mais se oferece a leituras e interpretações, porém, paradoxalmente, é aquele cujas atividades propostas mais reduzem as possibilidades de interação e multiplicidade de sentidos. Textos que poderiam contribuir para o entendimento de mundos simbólicos de escritores e leitores, seus contextos históricos, suas formas linguísticas, seus gêneros e seus múltiplos níveis de significados são reduzidos a uma racionalidade linear e superficial, simplificados de tal forma que não há, sequer, possibilidades de dúvidas.

Outra questão que merece reflexão para contribuir com as estratégias aqui sugeridas é a seleção dos textos utilizados para alfabetizar. Os textos utilizados pelas cartilhas e livros de alfabetização, de paradigmas tradicionais, representavam a garantia de seriação, controle e gradação das supostas dificuldades de leitura. Tudo cuidadosamente sequenciado, do mais simples para o mais complexo, textos curtos, de circulação exclusivamente escolar, compostos só de palavras já conhecidas e estudadas, ou de palavras cujas sílabas e suas respectivas famílias estivessem dominadas. Supunham assegurar, desta forma, que os alunos pudessem viver as suas experiências com a língua escrita como uma sequência didática, pedagogicamente organizada. Guardavam em seus fundamentos a crença de que, pela observância dos critérios que regiam a seleção dos textos, estariam garantindo o controle e o sucesso da atividade de leitura, formando leitores motivados para essa ação. Do mesmo modo, os textos reais, quando submetidos à didática e à metodologia subjacente aos livros e manuais didáticos, servem ao mesmo autoritarismo que permeia as relações de ensino. São tratados da mesma forma pragmática que desconsidera o interesse, o desenvolvimento 
e as experiências de vida dos alunos. Deste modo, admitir diversos gêneros de textos nas práticas de alfabetização, ao contrário do que se acreditou, não tem representado a realização de um trabalho que garanta aos alunos os conhecimentos necessários sobre como o sistema da escrita funciona.

Quanto à produção textual, ao se pensar em práticas no contexto escolar, uma questão que merece ser levantada diz respeito aos modos como a escola pode contribuir para a emergência da criatividade e de autoria no uso dos diferentes gêneros discursivos, orais ou escritos. Muitas vezes, acredita-se na ideia equivocada de que os processos criativos não possam ser desenvolvidos ou motivados também pela mediação dos professores. Neste sentido, o trabalho da escola para desenvolver a criatividade se concentra em jogos e brincadeiras que geralmente são colocados em maior evidência na educação infantil. Nos anos escolares subsequentes, a prioridade concedida aos aspectos formais da língua deixa outras possíveis atividades criativas em segundo plano. Deste modo, pouco se investe em atividades voltadas para o desenvolvimento da criatividade, principalmente no que tange ao ensino da produção de textos no ensino fundamental, especialmente nos anos iniciais.

De modo recorrente, o aluno é levado a escrever sobre um tema em atividades mecanicistas, sem receber nenhum subsídio para aprimorar sua expressão verbal. Observa-se que, sem contar com a mediação docente, os alunos colocam em jogo todos os conhecimentos que possuem, mas muitas vezes contam apenas com a inspiração para realizar a tarefa.

A criatividade é inerente às atividades de interação verbal. Contudo, toda troca linguística, toda elaboração discursiva, é dependente das condições histórico-culturais em que se encontra inserida (CARVALHO, 2011). Assim, haverá maior ou menor grau de criatividade e autoria, dependendo do contexto de interação em que os enunciados são produzidos. Tal posicionamento vincula o trabalho para a constituição da escrita, da leitura e da oralidade em função de práticas nas quais os textos (escritos ou falados) ganhem sentido.

Desse modo, o professor pode ter em mente que o trabalho vinculado à aprendizagem e uso da linguagem precisa desenvolver-se em função de práticas em que a escrita e a fala produzam sentido, tornando-se necessárias para o aprendiz em situações de troca com seus pares. Propor reflexões sobre o sistema alfabético de escrita representa também possibilitar o acesso e a construção de diferentes produções discursivas, 
permitindo aos alunos - afastados de uma concepção mecânica acerca da linguagem falar ou escrever, de fato, algo a alguém. Pois, conforme salienta Geraldi,

[...] para a produção de qualquer unidade discursiva é necessário considerar que: a) se tenha o que dizer; b) se tenha uma razão para dizer o que se tem a dizer; c) se tenha para quem dizer o que se tem a dizer; d) o locutor se constitua como tal, enquanto sujeito que diz o que diz para quem diz [...]; se escolham as estratégias para realizar (a), (b), (c), (d) (GERALDI, 1997, p. 137).

Vale ainda salientar que, considerando que nenhum texto se encontra acabado, sendo passível de reformulação e aperfeiçoamento, cabe ao professor propor ao aluno novas versões, problematizando diversos pontos, favorecendo, portanto, o processo de criação. Sendo assim, certas lacunas deixadas no texto podem ser reelaboradas a partir de provocações propostas pelo professor ou por colegas de turma. Deste modo, o ato criativo na produção escrita tem a ver também com a dinâmica de ler e ser lido por outros companheiros de sala de aula. Enfim, para que a escola contribua para a emergência da criatividade e da autoria na produção textual é preciso que o professor contemple atividades que possibilitem ao aluno: se constituir como sujeito do seu dizer; se colocar na posição de autor do discurso que vai mobilizar seu interlocutor na construção do sentido do seu texto.

\section{Considerações Finais}

Com base no que foi discutido, importa destacar que os componentes curriculares da formação em serviço de professores não representam entrave ao ensino, ou seja, não são os vilões da alfabetização. A questão é que professores e alunos têm sido conduzidos a vivenciar os conteúdos através de experiências curriculares desprovidas de perspectivas históricas, sem compromisso com a aprendizagem e a inserção sociocultural. Perde-se, neste percurso, a sintonia entre o tempo escolar e o tempo da aprendizagem. Em síntese, a recomendação é para que escapemos da ingênua neutralidade das escolhas de procedimentos metodológicos. Os modos de ensinar, para guardarem coerência com os processos de significação e a constituição dos indivíduos, precisam livrar as práticas escolares de um mundo de conhecimentos escolarizados superficiais, e de uma pedagogia que reproduz a lógica que não reconhece os indivíduos como seres que pensam e produzem conhecimento, nas quais professores e alunos acabam sendo 
vítimas do mesmo processo de esvaziamento e desqualificação pessoal, cultural e profissional.

Diversos referenciais (SMOLKA, 1993; CAGLIARI, 1998; FERREIRO; TEBEROSKY, 1999; CURTO; MORILLO; TEIXIDÓ, 2001), entre outros (GONTIJO, 2003; 2008; GOULART; GONÇALVES, 2013; LOPES, 2016) contribuem para a reflexão sobre o dia-a-dia do trabalho alfabetizador. Observa-se, ainda, publicações a partir da elaboração dos PCN que buscam a transposição didático-pedagógica de seus princípios teóricos. A proposta de formação do PROFA - Programa de Formação de Alfabetizadores (BRASIL, 2001), por exemplo, já se referia a algumas estratégias didático-pedagógicas aqui sugeridas.

Sinaliza-se, portanto, que os princípios teóricos que dão base a este artigo têm sua discussão iniciada há longo tempo. Contudo, ainda não concorrem para mudanças efetivas na prática dos professores. Compreende-se, a partir destes estudos, que as práticas em alfabetização só se efetivam em formação escolar para inclusão social se contextualizadas. Tais estudos ampliam o repertório didático, mas não precisam ser compreendidos como metodologia. Busca-se, todavia, reunir caminhos que possam representar princípios para estratégias didático-pedagógicas que contemplem a alfabetização. A teoria que se elabora a partir disto pressupõe que a formação do professor alfabetizador está constantemente em ação, de modo que possa contemplar contextos sempre novos de alunos a serem bem formados.

As estratégias didático-pedagógicas que vislumbrem modos contextuais de interação com a cultura escrita serão: a) Autorais, quando elaboradas ou selecionadas pelo professor, num processo que articule intencionalidade pedagógica, criatividade e marcas pessoais de fazer-se professor; b) Investigativas, se responderem às demandas reais de aprendizagem do aluno e do grupo, individualmente e coletivamente o tempo todo; c) Diversificadas, ao atenderem à diversidade original do ser humano e à subjetividade também inerente a ele.

Deste modo, a elaboração de planejamentos diversificados está relacionada à eleição de atitudes docentes pautadas em princípios educativos, centrados na relação entre as análises contextuais feitas pelos professores e o atendimento à real demanda de estudantes com a qual se trabalha. A adesão a um método exclusivo de trabalho para se colocar em prática os componentes curriculares escolares não faz parte destes princípios, exatamente por ser uma escolha que, a priori, delimita os planos de ação, 
subjugando previamente os percursos de aprendizagem dos estudantes.

Vygotsky (1998a, 1998b), como pesquisador que valoriza mais o processo do que o ponto de chegada, é um aporte para a seleção de propostas didáticas que desafiem os estudantes na medida certa, como oportunidades para que os mesmos sejam motivados em seus processos cognitivos, interajam com culturas diversas e, a partir destas bases intelectuais, produzam novos comportamentos, novas formas de ser e estar no mundo. Uma medida para selecionar as estratégias didático-pedagógicas é também verificar se são desafios possíveis de serem resolvidos, que estejam em consonância com as conquistas de aprendizagem que os alunos já alcançaram e com os conceitos espontâneos ou científicos já elaborados.

Destaca-se que, para formar os tão sonhados leitores críticos, não é suficiente oferecer aos alunos o contato com diferentes gêneros discursivos ou reter-se em discussões críticas acerca dos mesmos. Tais práticas são importantes, mas o contato com os textos e os debates não proporcionam o desenvolvimento de outros conhecimentos essenciais para ler com autonomia. A interação com o texto escrito pressupõe: a) Propriedades motoras específicas que envolvem postura física, domínio viso-motor, organização espacial e motricidade grafo-motora; b) Propriedades cognitivas e afetivas de elaboração de conceitos, apreensão e produção de sentidos; c) Propriedades culturais que abarcam inferências e diálogos entre as culturas nas quais os alunos transitam e a cultura escolar.

Deste modo, chama-se a atenção para a necessidade de se pensar uma formação para a alfabetização que possibilite ao professor apreender que as ações pedagógicas precisam ser planejadas conforme a realidade da sala de aula, considerando-se: quem são os alunos, seus modos de ser e aprender, seu desenvolvimento psicomotor, psicológico e cognitivo, suas realidades sociais e culturais, seus conhecimentos e suas vivências.

Contudo, para que o professor seja capaz de compreender os modos de elaboração de conhecimento de seus alunos, refletir sobre o cotidiano escolar e estar atento à intencionalidade de suas ações pedagógicas, com segurança em suas escolhas metodológicas, é preciso que sua formação contribua, ao mesmo tempo - conforme apontado por Machado, Lopes e Senna (2015) -, para a fundamentação teórica e a viabilização de modos de articulação dos conhecimentos teóricos com a prática pedagógica.

Conclui-se, assim, que as questões didáticas precisam ser incorporadas à for- 
mação dos professores alfabetizadores como estratégias pedagógicas para o diálogo entre as diferentes culturas que se entrecruzam nas escolas. Pressupõe-se, portanto, que o investimento nos aspectos didáticos seja ancorado em princípios inclusivos e disponíveis para escolas reais, alunos reais e, somente assim, havendo inserção de professores em projetos contínuos de formação em serviço.

\section{Referências Bibliográficas}

BAGNO, M. Preconceito linguístico: o que é, como se faz. 51. ed. São Paulo: Edições Loyola, 2009.

BRASIL. Ministério da Educação. Secretaria de Educação Fundamental. Parâmetros Curriculares Nacionais: língua portuguesa. Brasília, DF, 1997.

- Ministério da Educação. Secretaria de Educação Fundamental. Programa de formação de professores alfabetizadores PROFA. Brasília, DF, 2001.

CAGLIARI, L. C. Alfabetizando sem bá-bé-bi-bó-bu. São Paulo: Scipione, 1998.

CANDAU, V. M. F. Magistério: construção cotidiana. Petrópolis, RJ: Vozes, 1997.

CARVALHO, J. R. Criatividade no processo de produção textual: imaginação, mediação e interações. In: ZACCUR, E. Alfabetização e letramento: o que muda quando muda o nome? Rio de Janeiro: Rovelle, 2011. p. 227-241.

CARVALHO, M. Guia prático do alfabetizador. 4. ed. São Paulo: Ática, 2003.

CURTO, L. M.; MORILLO, M. M.; TEIXIDÓ, M. M. Escrever e ler: como as crianças aprendem e como o professor pode ensina-las a ler e a escrever. Porto Alegre: Artmed, 2001. v. 1.

FERreiro, E.; TEBerosky, A. A psicogênese da língua escrita. Porto Alegre: Artmed, 1999.

GERALDI, J. W. Portos de passagem. São Paulo: Martins Fontes, 1997.

GOÉS, M. C. R. A natureza social do desenvolvimento psicológico. Cadernos CEDES, v. 24, p. 21-29, 2000.

GONTIJO, C. M. M. A escrita infantil. São Paulo: Cortez, 2008. 
GONTIJO, C. M. M. Alfabetização: a criança e a linguagem escrita. Campinas: Autores Associados, 2003.

GOULART, C. M. A.; GONÇALVES, A. V. Aspectos semióticos da aprendizagem inicial da escrita. In: GOULART, C. M. A.; WILSON, V. (Orgs). Aprender a escrita, aprender com a escrita. São Paulo: Summus, 2013. p. 21-42.

LOPES, P. S. V. C. Alfabetização: produção textual: módulo 2 1: Interações Pedagógicas. Rio de Janeiro: Secretaria de Educação, 2016.

MACHADO, M. L. C. A. A escrita alfabética, sua natureza e representação: contribuições à Fonoaudiologia aplicada à Educação. 2013. 159 f. Tese (Doutorado)- Faculdade de Educação, Universidade do Estado do Rio de Janeiro, Rio de Janeiro, 2013.

MACHADO, M. L. C. A.; LOPES, P. S. V. C. A formação de professores para os anos iniciais do ensino fundamental na área de letramento e alfabetização para crianças, jovens e adultos. In: CONGRESSO BRASILEIRO DE ALFABETIZAÇÃO: POLÍTICAS PÚBLICAS DE ALFABETIZAÇÃO, 2., Recife, 2015. Recife. Anais... Recife: Associação Brasileira de Alfabetização, 2015.

MACHADO, M. L. C. A.; LOPES, P. S. V. C.; SENNA, L. A. G. La formación del professorado en Brasil: entre la cultura escrita y la diversidade cultural. Revista Temas de Educación, v. 21, n. 2, p. 311-326, 2015.

MACHADO, M. L. C. A.; SENNA, L. A. G. As políticas públicas inclusivas e o sujeito do fracasso escolar. Revista Aleph, v. 18, p. 45-58, 2012.

MENDONÇA, O. S.; MENDONÇA, O. C. Alfabetização: método sociolinguístico: consciência social, silábica e alfabética em Paulo Freire. São Paulo: Cortez, 2007.

MORTATTI, M. R. L. Os sentidos da alfabetização: São Paulo - 1876/1994. São Paulo: Ed. da UNESP, 2000.

SENNA, L. A. G. Psicogênese da língua escrita, universais linguísticos e teorias de alfabetização. Alfa, v. 39, p. 22 1-241, 1995.

. Psicolinguística e sistemas gramaticais no campo da psicopedagogia. In: GODOY, E.; SENNA, L. A. G. Psicolinguística e letramento. Curitiba: IBPEX, 2011. p. 129194.

SMOLKA, A. L. B. A criança na fase inicial da escrita: a alfabetização como processo discursivo. 2. ed. São Paulo: Cortez, 1993. 
SPALA, F. T. Da palavra falada à palavra da escola: um estudo sobre as orientações didáticas à alfabetização na cidade do Rio de Janeiro. 2015. 209 f. Tese (Doutorado)- Faculdade de Educação, Universidade do Estado do Rio de Janeiro, Rio de Janeiro: 2015.

VYGOTSKY, L. S. A formação social da mente. São Paulo: Martins Fontes, 1998a. . Pensamento e linguagem. São Paulo: Martins Fontes, 1998b.

Submissão: $10-02-2018$

Aceite: $22-08-2018$ 